\title{
Management of incomplete and missed spontaneous abortions: a cohort study of trends in Calgary emergency departments
}

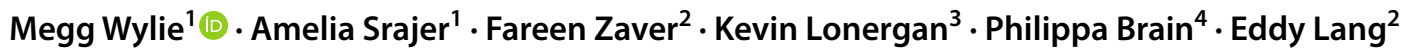

Received: 16 July 2021 / Accepted: 20 January 2022 / Published online: 3 March 2022

(C) The Author(s), under exclusive licence to Canadian Association of Emergency Physicians (CAEP)/ Association Canadienne de Médecine d'Urgence (ACMU) 2022

\begin{abstract}
Objectives Incomplete and missed spontaneous abortion cases often first present to the emergency department (ED), where they can be managed operatively via dilation and curettage (D\&C) or non-operatively through medical or expectant management. The primary objective of this study was to determine how rates of operative management have changed over time across Calgary EDs. The secondary objective was to assess correlates of effectiveness and potential drivers in management including gynecological consults, ED return visits requiring admission, and subsequent D\&Cs.

Methods Sunrise Clinical Manager (electronic medical system) was accessed to collect data for patients who presented to a Calgary ED with an incomplete or missed spontaneous abortion from 2014 to 2019. Patients requiring resuscitation and those with complications were excluded. Return to care for D\&C and ED revisits requiring admission were used as a proxy for failed non-operative management. Trends in management are reported using 95\% confidence intervals.

Results Of the 3845 patients included, 1110 (28.9\%) received a D\&C on initial ED visit. The remaining 2735 (71.1\%) were initially managed non-operatively. Rates of D\&Cs decreased $11.6 \%$ from 2014 to 2019, 95\% CI (6.5\%, 16.8\%). There was minimal change in the rates of gynecological consults, ED returns requiring admission, and returns to care resulting in D\&Cs over time.

Conclusions The management of incomplete and missed spontaneous abortions has shifted toward non-operative management over 6 years in Calgary. As this is not associated with increased ED returns requiring admission or subsequent D\&Cs, the shift appears to be appropriate. As gynecological consults were consistent over time, further knowledge translation around non-operative spontaneous abortion management may be useful for ED physicians.
\end{abstract}

Keywords Spontaneous abortion $\cdot$ Miscarriage $\cdot$ Misoprostol $\cdot$ Dilatation and curettage $\cdot$ Emergency medicine $\cdot$ Obstetrics and gynecology

\section{Résumé}

Objectifs Les cas d'avortement spontané incomplets et manqués sont souvent les premiers à se présenter au service d'urgence (SU), où ils peuvent être gérés opérationnellement par dilatation et curetage (D\&C) ou non opératoire par une prise en charge médicale ou d'attente. Le principal objectif de cette étude était de déterminer comment les taux de prise en charge opératoire ont changé au fil du temps dans les SU de Calgary. L'objectif secondaire était d'évaluer les corrélats de l'efficacité et

Megg Wylie

megg.wylie@ucalgary.ca

1 Cumming School of Medicine, University of Calgary, 204-1331 14th Avenue SW, Calgary, AB T3C 0W3, Canada

2 Department of Emergency Medicine, University of Calgary, Calgary, AB, Canada

3 Alberta Health Services, University of Calgary, Calgary, AB, Canada

4 Department of Obstetrics and Gynecology, University of Calgary, Calgary, AB, Canada 
les facteurs potentiels de la prise en charge, notamment les consultations gynécologiques, les visites de retour aux urgences nécessitant une admission et les D\&C ultérieures.

Méthodes Sunrise Clinical Manager (système médical électronique) a été consulté pour recueillir les données des patients qui se sont présentés à un service d'urgence de Calgary avec un avortement spontané incomplet ou manqué entre 2014 et 2019. Les patients nécessitant une réanimation et ceux présentant des complications ont été exclus. Le retour aux soins pour une D\&C et les nouvelles visites aux urgences nécessitant une admission ont été utilisés comme indicateur de l'échec de la prise en charge non opératoire. Les tendances en matière de gestion sont signalées en utilisant des intervalles de confiance à $95 \%$. Résultats Sur les 3845 patients inclus, $1110(28,9 \%)$ ont reçu un D\&C lors de la première visite à l'urgence. Les 2735 autres $(71,1 \%)$ ont été initialement pris en charge de manière non chirurgicale. Les taux de D\&C ont diminué de 11,6\% entre 2014 et 2019, IC à 95\% $(6,5 \%, 16,8 \%)$. Il y a eu un changement minime dans les taux de consultations gynécologiques, de retours aux urgences nécessitant une admission et de retours aux soins entraînant des D\&C au fil du temps.

Conclusions La prise en charge des avortements spontanés incomplets et manqués a évolué vers une prise en charge non opératoire en 6 ans à Calgary. Comme cela n'est pas associé à une augmentation des retours à l'urgence nécessitant une admission ou des D\&C ultérieurs, le changement semble être approprié. Les consultations gynécologiques étant constantes au fil du temps, une application plus poussée des connaissances sur la prise en charge des avortements spontanés non opératoires pourrait être utile aux médecins des urgences.

\section{Clinician's capsule}

What is known about the topic?

Awareness of non-operative management as an appropriate treatment for spontaneous abortion, which often presents to the ED, is increasing.

\section{What did this study ask?}

How management of incomplete and missed spontaneous abortion in Calgary EDs has changed over time.

\section{What did this study find?}

Rates of operative spontaneous abortion management decreased from $34.2 \%$ in 2014 to $22.6 \%$ in 2019.

\section{Why does this study matter to clinicians?}

With knowledge translation of study results there could be a further practice shift toward non-operative ED management of spontaneous abortion.

\section{Introduction}

Spontaneous abortion, otherwise termed miscarriage, is pregnancy loss prior to 20 weeks gestation [1]. People with early pregnancy concerns often present to the ED with symptoms such as vaginal bleeding [2]. Diagnosis of spontaneous abortion is based on clinical presentation, cervical examination, and ultrasound findings [1]. A spontaneous abortion is defined as incomplete when some, but not all, products of conception have been passed [1]. Missed spontaneous abortion is fetal demise without uterine activity, resulting in retained products of conception [1]. Incomplete and missed spontaneous abortions can be managed operatively or non-operatively. Dilation and curettage (D\&C) is an operative approach in which the cervix is dilated and products of conception are removed from the uterus [1]. A $\mathrm{D} \& \mathrm{C}$ is invasive and carries the risks of a surgical procedure, though in some high acuity cases D\&C is indicated as definitive management [1]. Non-operative approaches to spontaneous abortions include medical or expectant management. Medical management is safe and effective [3-5] and involves a prostaglandin analog medication (i.e., misoprostol) that promotes evacuation of uterine contents, with associated symptoms of cramping and vaginal bleeding [6]. Alternatively, expectant management allows for products of conception to pass spontaneously without medication [5]. The success of expectant management varies [7], with a meta-analysis demonstrating success from 39 to $78 \%$ [7].

Though the ED is a site of presentation for spontaneous abortions [2], it is unclear how spontaneous abortion management in the ED has changed in Calgary over recent years. Within Calgary, there are four ED sites, each with high patient volumes. It was our expectation that over the period of assessment, management rates would change due to increased awareness of non-operative strategies as appropriate treatment options, which may contribute to a decrease in D\&Cs.

Gaining a better understanding of if and how ED management of incomplete and missed spontaneous abortion has changed over time may direct a need for increased or modified knowledge translation. The primary objective of this study was to determine how the management of incomplete and missed spontaneous abortion in Calgary EDs has changed from 2014 to 2019, to assess practice variation and trends between non-operative and operative management. The secondary objective was to assess ED correlates of effectiveness and potential drivers in management, including gynecological consults, ED returns requiring admission and need for a subsequent D\&C. 


\section{Methods}

Sunrise Clinical Manager (SCM), an electronic medical system utilized in Calgary to track patient and department information, was used to collect patient data. Patients who presented to one of four Calgary EDs over a 6-year time frame (January 1, 2014, to December 31, 2019) with International Classification of Disease (ICD-10) diagnosis codes O03.4 (incomplete spontaneous abortion without complication) or O02.1 (missed abortion) were included [8]. Threatened abortions, which are defined by a potentially viable fetus, were not included as expectant management is the standard of care [1]. Complete abortions were not included as these are defined by the complete expulsion of uterine contents without need for further intervention [1].

Patients were excluded if they had multiple diagnoses, missing regional health record numbers (RHRNs), a Canadian Triage and Acuity Scale (CTAS) code of 1 (required resuscitation), or a complex admit status (not classified as admitted or discharged). Patients without RHRNs were excluded because RHRNs are required to confirm a unique patient visit. Patients with a complex admit status were excluded because we could not determine the definitive management of these patients (i.e., if they left without being seen or against medical advice).

Patient factors including hospital identification number, CTAS code, age and gender were collected. Variables including $\mathrm{D} \& \mathrm{C}$ procedures (initial or subsequent), gynecological consults, ED returns within 7 days and those returns which required admission were collected. The success of non-operative management was indirectly measured via ED returns requiring admission and by returns to care for subsequent D\&Cs. Returns to care for subsequent D\&Cs included both inpatient and ambulatory D\&Cs. Trends in management were analyzed using Chi-square $\left(X^{2}\right)$ tests and reported with $95 \%$ confidence intervals. Analyses were conducted using IBM SPSS Statistics for Windows, version 26.0 (IBM Corp., Armonk, NY, USA). The study was reviewed and approved by the Conjoint Health Research Ethics Board at the University of Calgary (REB20-2189). Due to ethical concerns, individual patient data cannot be made publicly available for data sharing.

\section{Results}

From 2014 to 2019, 4617 patients presented to one of four Calgary EDs who were classified as having either an incomplete spontaneous abortion without complication or a missed abortion. Patients were excluded if they had multiple diagnoses $(n=695)$, missing patient identification numbers $(n=2)$, a CTAS score of $1(n=5)$, or a complex admit status $(n=70)$.

Among the 3845 included patients, the mean age was $32.9 \pm 5.9$ years (range $15.3-51.5$ years). Of these patients, $1699(44.2 \%)$ received a gynecological consult during their ED visit. For the 2146 patients who did not receive a gynecological consult, ED physicians remained their responsible care provider. 1110 patients $(28.9 \%)$ received a D\&C at their initial ED presentation and the remaining $2735(71.1 \%)$ patients were managed non-operatively. 768 (20.0\%) patients returned to the ED within 7 days and 293 (38.2\%) of these returning patients were admitted. Of the 768 patients who returned, $519(67.6 \%)$ did not receive a gynecological consult at their initial presentation and 710 (92.4\%) were initially managed non-operatively. Of the 2735 patients who received non-operative management at their initial ED visit, 416 (15.2\%) received a subsequent D\&C, at either an inpatient or ambulatory setting, within 7 days.

D\&C rates decreased from $34.2 \%$ in 2014 to $22.6 \%$ in 2019 , an absolute reduction of $11.6 \%, 95 \%$ CI $(6.5 \%$, $16.8 \%$ ) (Fig. 1). This difference remained significant when compared across all 6 years $(p<0.001)$. Despite decreasing $\mathrm{D} \& \mathrm{C}$ rates over time, there was minimal change in 7-day ED returns requiring admission [95\% CI $(-4.0 \%, 21.3 \%)]$, subsequent D\&Cs [95\% CI $(-1.3 \%, 8.3 \%)]$, and gynecological consults [95\% CI $(-4.9 \%, 6.3 \%)$ ] between 2014 and 2019. ED return rates decreased 5.2\% from 2014 to 2019, 95\% CI $(0.7 \%, 9.8 \%)$. However, this difference was non-significant when compared across all 6 years.

\section{Discussion}

\section{Interpretation of findings}

The rate of D\&C management for spontaneous abortions has decreased in Calgary. An absolute reduction of $11.6 \%$ and a relative reduction of $33.9 \%$ over 6 years was observed. This reduction was associated with a corresponding increase in non-operative management and without an increase in failed non-operative management. ED returns requiring admission and returns to care for D\&Cs were consistent from 2014 to 2019. The year of presentation did not influence gynecological consult rates, despite decreasing $\mathrm{D} \& \mathrm{C}$ rates.

\section{Comparison to previous studies}

The shift toward non-operative management appears to be appropriate given that our measures for failure of non-operative management remained stable over time. Similar shifts in spontaneous abortion management have been observed elsewhere. A retrospective study in Finland described that between 1996 and 2016, spontaneous abortion management 
Fig. 1 Change in spontaneous abortion management across Calgary EDs from 2014 to 2019. Results are represented as percentages of the total number of spontaneous abortion presentations to Calgary EDs each year. Subsequent D\&Cs included both inpatient and ambulatory D\&Cs performed within 7 days of the initial visit. ED returns and returns requiring admission included patients who represented to the ED within 7 days of their initial visit. $D \& C$ dilation and curettage, $E D$ emergency department

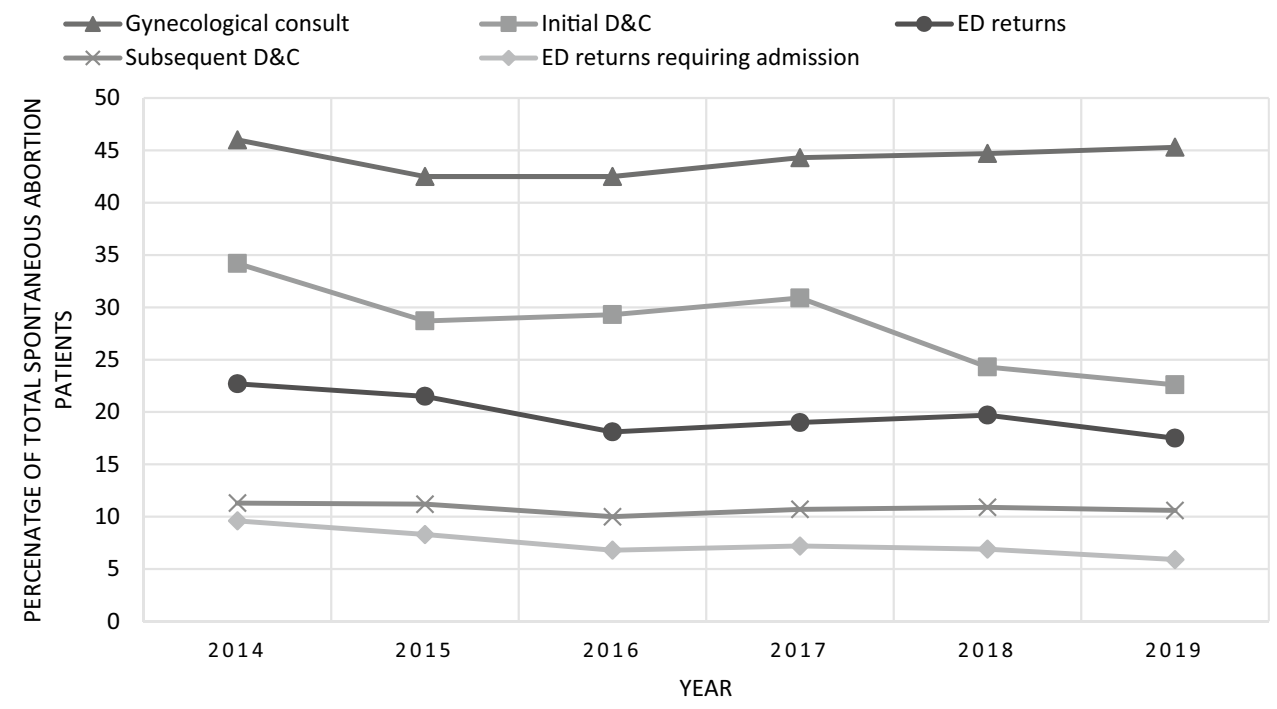

shifted toward non-operative management, with a marked reduction in D\&Cs [9]. This shift was substantial enough that non-operative management was considered the new standard of care in Finland [9].

\section{Strengths and limitations}

As SCM data is manually entered by clinicians, it is possible errors in charting may have occurred. We reduced discrepancies through careful review of irregular data entries. We were unable to determine how individual patient diagnoses were made prior to SCM entry. One site was connected to an early pregnancy loss clinic and may have had varied practice patterns. The study was limited to patients with incomplete and missed spontaneous abortions and is not representative of all spontaneous abortions.

\section{Research and clinical implications}

While the observed shift in practice may be related to changes in ED physician practice, one must also consider the influence of gynecological physicians, as gynecological consult rates were consistent throughout 2014-2019 despite management shifts. However, 55.8\% of patients included did not receive a gynecological consult, and ED physicians remained their responsible care provider. As such, further knowledge translation around non-operative spontaneous management targeted toward ED physicians is necessary. It is possible a more marked shift in practice could be observed if care providers involved in ED management of spontaneous abortion are aware and accepting of non-operative management as a safe and effective treatment option.

This practice shift may also be related to shared decision making between ED physicians, gynecologists, and patients [10]. Psychosocial factors as well as prior healthcare experiences can influence management preferences of patients experiencing pregnancy loss [10]. There have been calls for increased patient-centred decision making in pregnancy loss care [10]. If implemented, shared decision making may have enabled patients to better understand the available management options and to have a greater voice in their treatment.

\section{Conclusion}

There has been a practice shift toward non-operative management of incomplete and missed spontaneous abortion in Calgary, with stable rates of failed non-operative management. Consistent gynecological consult rates suggest this shift may be driven by gynecologists and there may be a need for further knowledge translation targeted toward ED physicians. We hope the current study will increase awareness and acceptance of medical and expectant management as effective treatment options for patients experiencing spontaneous abortion in the ED.

Funding None.

Availability of data and material Not available.

Code availability Not applicable.

\section{Declarations}

Conflict of interest None.

Ethics approval The study was reviewed and approved by the Conjoint Health Research Ethics Board at the University of Calgary (REB202189).

Consent to participate Not applicable. 
Consent for publication All of the contributing authors confirm that this manuscript has not been previously published and is not currently under consideration by any other journal. Additionally, all of the authors have approved the contents of this paper and have agreed to the CJEM's submission policies. All authors consent for publication of the above manuscript.

\section{References}

1. Griebel C, Halvorsen J, Golemon TB, Day AA. Management of spontaneous abortion. Am Fam Physician. 2005;72(7):1243-50.

2. Warner A, Saxton A, Indig D, Fahy K, Horvat L. Women's experience of early pregnancy care in the emergency department: A qualitative study. Australas Emerg Nurs J. 2012;15(2):86-92.

3. Al-Wattar HB, Murugesu N, Tobias A, Zamora J, Khan K. Management of first-trimester miscarriage: a systematic review and network meta-analysis. Hum Reprod Update. 2019;25(3):362-74.

4. Mizrachi Y, Ben-Ezry E, Kleiner I, Friedman G, Kerner R, Bar $\mathrm{J}$, et al. Reproductive outcome after early pregnancy loss treated with misoprostol versus surgical aspiration. Reprod Biomed Online. 2020;41(4):707-13.
5. Trinder J, Brocklehurst P, Porter R, Read M, Vyas S, Smith L. Management of miscarriage: expectant, medical, or surgical? Results of randomised controlled trial (Miscarriage Treatment [MIST] Trial). Obstet Gynecol. 2006;108(2):450.

6. Allen R, O'Brien B. Uses of misoprostol in obstetrics and gynecology. Rev Obstet Gynecol. 2009;2(3):159-68.

7. Sotiriadis A, Makrydimas G, Papatheodorou S, Ioannidis J. Expectant, medical, or surgical management of first-trimester miscarriage: a meta-analysis. Obstet Gynecol. 2005;105(5, Part 1):1104-13.

8. World Health Organization. ICD-10: international statistical classification of diseases and related health problems. Geneva: World Health Organization; 2004.

9. Linnakaari R, Helle N, Mentula M, Bloigu A, Gissler M, Heikinheimo $\mathrm{O}$, et al. Trends in the incidence, rate and treatment of miscarriage-nationwide register-study in Finland, 1998-2016. Hum Reprod. 2019;34(11):2120-8.

10. Schreiber C, Chavez V, Whittaker P, Ratcliffe S, Easley E, Barg F. Treatment decisions at the time of miscarriage diagnosis. Obstet Gynecol. 2016;128(6):1347-56. 